\title{
MICROSURGICAL CLIPPING OF A PREVIOUSLY COILED ANTERIOR COMMUNICATING ARTERY ANEURYSM
}

\author{
Assoc. Prof. Doga Gurkanlar ${ }^{1}$, MD., Assoc.Prof. Sevda Lafcı Fahrioglu2* \\ 1:Near East University Faculty of Medicine, Dept. of Neurosurgery, Nicosia, Cyprus \\ 2:Near East University Faculty of Medicine, Dept. of Anatomy, Nicosia, Cyprus \\ e-mail: sevdalafci@gmail.com
}

\begin{abstract}
Introduction: Previously coiled recurrent or residual aneurysms require different and more complex microsurgical techniques in order to securely place the aneurysm clip for definite and complete closure of the aneurysm. Material-Method: We present our surgical experience in the microsurgical neck clipping of our patient, 54 year-old male, harboring a previously coiled anterior communicating artery aneurysm. Conclusion: The high quality performed surgical clipping is preferable treatment modality particularly in recurrent previous coilled intracranial aneurysm
\end{abstract}

Keywords: intracranial aneurysm; endovascular coiling, surgical clipping 


\section{INTRODUCTION}

Intracranial aneurysms are abnormal enlargements that progress with degeneration of the arterial wall in the intracranial vessel system and occurs especially in the bifurcation of the vessels. They are classified based on their anatomic location, size, and morphology. Abnormal dilation of the vessel is very unstable. This instability can cause the rupture of the aneurysm. James et al. (2018) suggest that it may lead to the subarachnoid hemorrhage which is the most devastating clinical picture of aneurysm with $40-60 \%$ mortality rate. The incidence of aneurysmal subarachnoid hemorrhage (aSAH) is 9-23 persons per 100000. Removing the aneurysm from the intracranial circulation by endovascular coiling or surgical clipping methods are the treatment options that protect the patient from bleeding or re-bleeding of the aneurysm. It was reported that almost $30 \%$ of unruptured aneurysms tend to bleed during lifetime period by Izumo $T$ et al. (2015).

The concept of coil instability is an important deficiency of endovascular treatment. According to research by Izumo T et al. (2015) the wall of the aneurysms is scarred by the intraaneurysmal coil masses or the coil adherent to the surrounding vital structures therefore surgical treatment of the recurrent coilled aneurysms may be difficult for the neurosurgeons. Retreatment of aneurysm is inevitable in the most treatment of patients with coil instability as reported by Molyneux AJ et al. (2009) and Raper DM et al. (2010).
Many studies have been conducted on the short- and long-term outcomes of neurosurgical clipping and endovascular coiling methods within 30 years of the first treatment of rupture cerebral aneurysm with endovascular coiling in 1990. According to research by Lanzino $G$. et al. (2006) endovascular treatment is a generally accepted treatment modality. It was supported by the study of Molyneux AJ. et al. (2005) which is named the International Subarachnoid Aneurysm Trial (ISAT) study. Recurrence or incomplete obstruction which causes rebleeding of the aneurysm is an important problem in endovascular coiling and is reported to be $17.4 \%$ as reported by Molyneux AJ, et al. (2002). The CARAT study which was conducted by CARAT Investigators (2006) reported that there was no significant difference in endovascular and surgical treatment at 1-year follow-up in terms of aneurysm rerupture $(0.11 \%-0 \%$, respectively). In the first year of follow-up, the need for retreatment was reported to be $7.7 \%$ in the coiling group and $1.7 \%$ in the surgical group. Aneurysm recurrence has been reported in up to $20 \%$ in endovascular treated cases in the study of Petr et al. (2015). Molyneux et al. (2015) reported that in patients treated with endovascular clipping, the risk of rebleeding of the aneurysm is not high but is still higher than surgical clipping. According to the latest 10-year follow-up analysis of the Barrow Ruptured Aneurysm Trial (BRAT) study; it was reported by 
Spetzler RF. et al. (2019) that there was no difference between endovascular method and surgical clipping in terms of death or functional dependence and the surgical clipping method had the best results in terms of obliteration of the aneurysm, need for new treatment, and incidence of rebleeding.

In summary, the Barrow Ruptured Aneurysm Trial (BRAT), conducted by Serrone JC. et al. (2015), the International Subarachnoid Aneurysm Trial (ISAT) conducted by Molyneux AJ. et al. (2015), and other randomized trial of ruptured cerebral aneurysms from Finland conducted by Spetzler RF. et al. (2019), reported that there was a little difference in clinical outcomes between the endovascular and the surgical treatment groups.

Herewith, we present our surgical experience in the microsurgical treatment of our patient harboring a previously coiled anterior communicating artery aneurysm.

\section{Case Description:}

A 54-year-old male patient presented to our clinic with progressive headache. The first coiling was performed 3 years earlier after rupture when he presented with subarachnoid hemorrhage of world federation of neurosurgical societies (WFNS) Grade 1.

His neurological examination did not reveal anything remarkable. The cerebral digital subtraction angiography (DSA) and magnetic resonance angiography (MRA) revealed a $10 \mathrm{~mm}$ unruptured anterior communicating artery (ACOM) aneurysm with a neck diameter of $5 \mathrm{~mm}$ It is classified as Class IIIb according to the Modified Raymond - Roy Classification (MRRC) [6] (Figurela and 1b). Because these MRRC Class Illb aneurysms are much more prone to rebleeding than the other types, we decided to proceed with microsurgical clipping. It was performed through the ipsilateral pterional approach (right pterional craniotomy), and the clip was placed in the neck of the aneurysm without intraaneurysmal coil removal (Figure $2 a$ and $2 b$ ).

Operative findings of coiled aneurysm were consistent with a thin, translucent and diaphanous aneurysm wall with compromised integrity, where coils could be observed directly through the aneurysm wall. Intraoperative Doppler ultrasound was used to assess blood flow through the anterior cerebral arteries. After the operation the patient had no neurological deficit and had an uneventful follow-up. His control MRA showed total aneurysm occlusion (Figure 3). The patient was invited for routine controls after discharge. During the threeyear follow-up, he had no problems or relapses.

\section{DISCUSSION}

J Powell. et al. (2002) reported that the endovascular coil modality is more widely used in the treatment of intracranial aneurysms as an alternative to craniotomy. Recurrence and rebleeding are the main risks after the coil application.

According a study conducted by Molyneux AJ. (2005) the Raymond-Roy 
occlusion classification (RROC) is a commonly used classification that determines the amount of occlusion that occurs in endovascularly treated intracranial aneurysms, but it is not used to evaluate of the risk of recurrence of the aneurysm. If there is complete occlusion in aneurysm underwent endovascular coiling defined as Class I, if residual neck is detected defined as Class II, if residual aneurysm is present defined as Class III. Latter aneurysms have a tendency to incomplete occlusion and rebleeding. Class III was examined in two subgroups in an article published by Moscitelli et al. (2015). According to their Modified RROC, if there was contrast opacification within the coil interstices of the residual aneurysm classified as Class Illa, if there was contrast opacification outside the coil interstices along the wall of the residual aneurysm classified as Class Illb. According to research by Mascitelli et al. (2015) study found that class Illa aneurysms progress to complete occlusion more than class IIIb aneurysms. The aneurysms in Class IIIb are very difficult to block with a coil because of its large size and wide neck.

According to Campi A. et al. (2007), Civit T. et al. (1999), Johnston SC., et al. (2007), although the aneurysm obliteration rates are significantly lower and retreatment rates are significantly higher in patients undergoing coiling than in those undergoing clipping endovascular coiling has been increasingly applied for the initial treatment of ruptured or unruptured intracranial aneurysms. The reported rates of aneurysm recurrence after initial endovascular treatment range from $3.6 \%$
- $40 \%$ in the same studies. In the acute stage, complex configuration of the aneurysm or under deliberate intention can lead to underpacking of ruptured aneurysms. In these cases, the need for further treatment is obvious. When repeated coiling is not possible, early microsurgical clipping of the remnant aneurysm should be considered as a definite therapeutic option was reported by Molyneux AJ et al. (2009). For this reason, we decided to perform microsurgical clipping in our patient, harboring Class Illb recurrent aneurysm with a wide neck due to the high rerupture risk.

Although the overall risk of rebleeding after coiling is low in general, rerupture rates of incompletely obliterated aneurysms were as high as $17.6 \%$ during a mean follow-up of 4 years, when less than $70 \%$ of the aneurysm was occluded as reported by Renowden SA, et al. (2008) and Raymond et al. (1997). Growing remnant aneurysms carry the highest risk of rerupture. According to Modified Raymond - Roy Classification (MRRC) which was explained in the study of Johnston S. et al. (2008), angiographic occlusion class is a predictor of aneurysm recurrence and rehemorrhage. According to research by Molyneux AJ. et al. (2015) in Class Illb recurrent aneurysms there is a gap between the coils and aneurysm wall. This kind of aneurysms usually have contrast opacification through a portion of the aneurysm neck with continuation along a portion of the aneurysm wall. Classlllb aneurysms usually have an area in the aneurysm neck without coils that can be potentiated by the inflow jet over time 
and prevent neck healing. Therefore, Classlllb group had larger aneurysms with wider necks. Class Illb aneurysms have higher retreatment rate and trend toward higher subsequent rupture rate. It is also not surprising that packing density (PD) was lower in the Classlllb group, as low PD has been associated with recurrence in previous studies which was conducted by Grunwald IQ. et al. (20013).

Previously coiled recurrent or residual aneurysms require different and more complex microsurgical techniques in order to securely place the aneurysm clip for definite and complete closure of the aneurysm. A totally different microsurgical procedure is required to completely obliterate residual or recurrent aneurysms in previously coiled patients. Although there are some classification systems to predict the rebleeding rates of previously coiled aneurysms, there is only limited experience in this group of patients according to Romani R. et al. (2011) and Waldron JS, et al. (2009). According to the result of the Cerebral Aneurysm Rerupture After Treatment (CARAT) Study (2009) which included 1010 patients, the annual retreatment rates in clipped patients were low than coiled patients. The results of the study conducted by Molyneux AJ. et al. (2009) the residual aneurysm neck which is the one of the problems after endovascular coiling that can be managed by surgical clipping, re-coiling or stent implantation.

Aneurysm recurrences due to coil compaction without changes in aneurysmal morphology can be effectively treated by additional coiling. Conversely, recurrences due to aneurysmal regrowth without coil compaction have a tendency to recur was reported by Sluzewski M. et al. (2005). Therefore, we have selected microsurgical clipping for remarkable aneurysmal regrowth or recurrent aneurysms with wide necks, and this policy led us to obtain the best results. For this reason, we decided to perform microsurgical clipping in our patient, harboring Class IIlb reccurrent aneurysm with a wide neck due to the high rerupture risk.

\section{CONCLUSION}

The microsurgical clipping is a successful method for the treatment of coiled aneurysm with incomplete occlusion, coil compression, or regrowth of the aneurysmal neck. As in our report, in patients classified as MRRC Class IIlb, direct neck clipping without removing the aneurysmal coil is the preferred treatment method in order to prevent aneurysm rerupture.

The high quality performed surgical clipping is preferable treatment modality particularly in recurrent previous coiled intracranial aneurysm.

Declaration of Interest: The authors declare that they have no known competing financial interests or personal relationships that could have appeared to influence the work reported in this paper.

Funding information: No funding was received for this study. 
Authorship of this case report has based

on substantial contributions to conception and design, acquisition of data, analysis and interpretation of data, drafting the article, revising it critically for important intellectual content, final approval of the version to be published.

Figure 1a: The cerebral digital subtraction angiography (DSA) shows coilled aneurysm in ACOM. ACOM: The anterior communicating artery

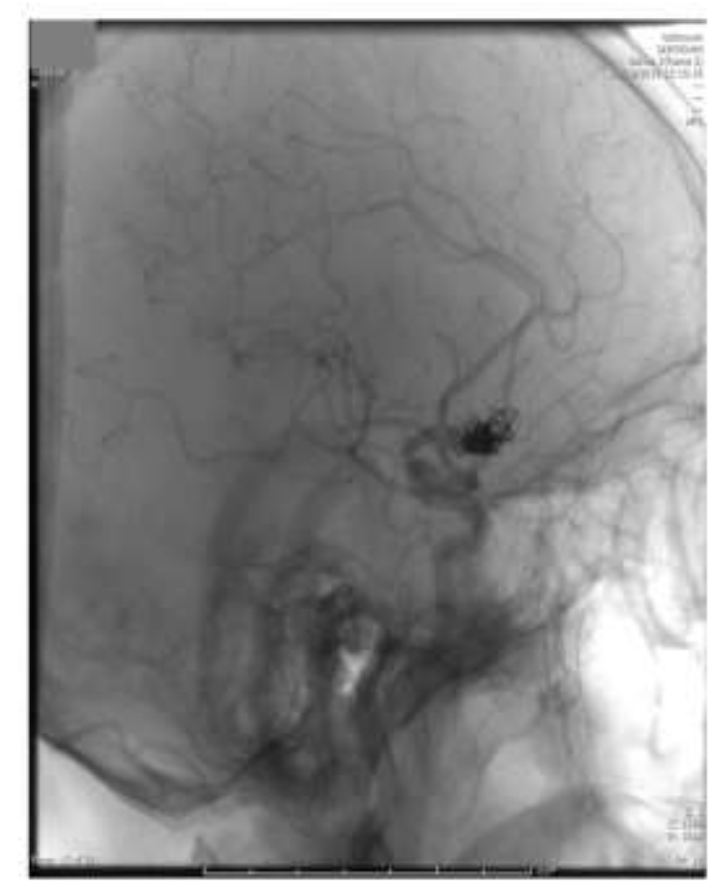


Figure 1b: The magnetic resonance angiography (MRA) shows the anterior communicating artery (ACOM) aneurysm with a neck diameter of $5 \mathrm{~mm}$.

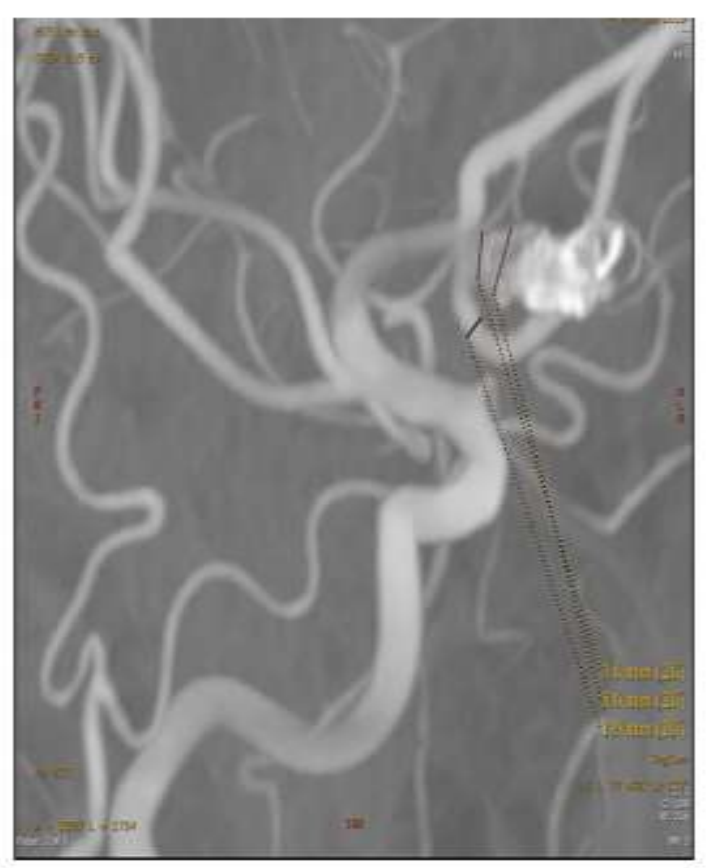

2021 January Edition | www.jbino.com | Innovative Association 
Figur 2a: The intraoperative picture shows the neck of the coilled aneurysm.

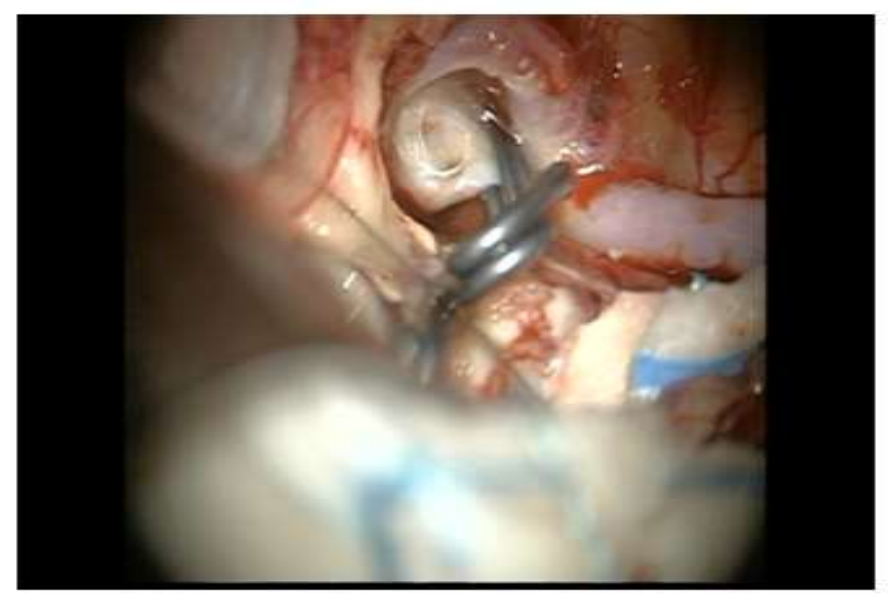

Figur 2b: The intraoperative picture shows the clip was placed across the neck of the aneurysm. 


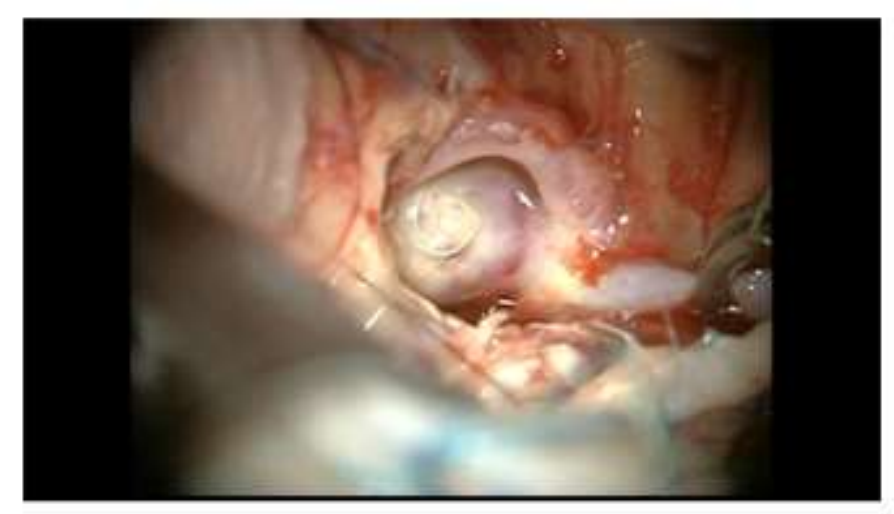

Figure 3: The figure shows total aneurysm occlusion in the MRA taken 1.5 years after microsurgical clipping. MRA: Magnetic resonance angiography

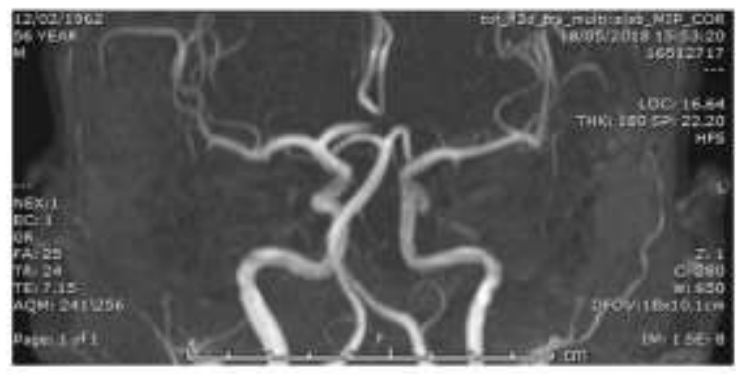

2021 January Edition | www.jbino.com | Innovative Association 


\section{REFERENCES}

James W, Berger GK, Benet A, Lawton MT. Surgical Clipping of Previously Ruptured, Coiled Aneurysms: Outcome Assessment in 53 Patients. World Neurosurg. 2018 Dec;120:e203-e211. doi: 10.1016/j.wneu.2018.07.293. Epub 2018 Aug 23.

Izumo T, Matsuo T, Morofuji Y, Hiu T, Horie N, Hayashi K, Nagata I. Microsurgical clipping for recurrent aneurysms after initial endovascular coil embolization. World Neurosurg. 2015 Feb;83(2):21 1-8. doi: 10.1016/j.wneu.2014.08.013. Epub 2014 Aug 10.

Molyneux AJ, Kerr RS, Birks J, Ramzi N, Yarnold J, Sneade $M$, Rischmiller J; Collaborators I: Risk of recurrent subarachnoid haemorrhage, death, or dependence and standardised mortality ratios after clipping or coiling of an intracranial aneurysm in the International Subarachnoid Aneurysm Trial (ISAT): longterm follow-up. Lancet Neurol 8:427-433, 2009.

Raper DM, Allan R: International subarachnoid trial in the long run: critical evaluation of the long-term follow-up data from the ISAT trial of clipping vs coiling for ruptured intracranial aneurysms. Neurosurgery 66:1166-1169 [discussion 1169], 2010.

Lanzino G, Fraser K, Kanaan Y, Wagenbach A: Treatment of ruptured intracranial aneurysms since the International Subarachnoid Aneurysm
Trial: practice utilizing clip ligation and coil embolization as individual or complementary therapies. J Neurosurg 104:344-349, 2006.

Molyneux AJ, Kerr RS, Yu LM, Clarke $M$, Sneade $M$, Yarnold JA, Sandercock P; Group ISATIC: International subarachnoid aneurysm trial (ISAT) of neurosurgical clipping versus endovascular coiling in 2143 patients with ruptured intracranial aneurysms: a randomised comparison of effects on survival, dependency, seizures, rebleeding, subgroups, and aneurysm occlusion. Lancet 366:809-817, 2005.

J Powell, N Kitchen, J Heslin, R Greenwood: Psychosocial outcomes at three and nine months after good neurological recovery from aneurysmal subarachnoid haemorrhage: predictors and prognosis. J Neural Neurosurg Psychiatry. 2002; 72: 772-781.

\section{Molyneux A, Kerr R, Stratton I, Sandercock} P, Clarke M, Shrimpton J, Holman R; International Subarachnoid Aneurysm Trial (ISAT) Collaborative Group. International Subarachnoid Aneurysm Trial (ISAT) of neurosurgical clipping versus endovascular coiling in 2143 patients with ruptured intracranial aneurysms: a randomised trial. Lancet. 2002 Oct 26;360(9342):1267-74.

CARAT Investigators. Rates of delayed rebleeding from intracranial aneurysms are low after surgical and endovascular treatment. Stroke. 2006 Jun;37(6):1437-42. Epub 2006 Apr 20. 
Petr O, Brinjikji W, Thomé C, Lanzino $\mathbf{G}$. Safety and efficacy of microsurgical treatment of previously coiled aneurysms: a systematic review and meta-analysis. Acta Neurochir (Wien). 2015 Oct;157(10):1623-32. doi: 10.1007/s00701015-2500-y. Epub 2015 Jul 14. Review. PMID: 26166207

Molyneux AJ, Birks J, Clarke A, Sneade M, Kerr RS. The durability of endovascular coiling versus neurosurgical clipping of ruptured cerebral aneurysms: 18 year follow-up of the UK cohort of the International Subarachnoid Aneurysm Trial (ISAT). Lancet. 2015 Feb $21 ; 385(9969): 691-7$. doi: 10.1016/S01406736(14)60975-2. Epub 2014 Oct 28.

Spetzler RF, McDougall CG, Zabramski JM, Albuquerque FC, Hills NK, Nakaji P, Karis JP, Wallace RC. Ten-year analysis of saccular aneurysms in the Barrow Ruptured Aneurysm Trial. J Neurosurg. 2019 Mar 8:1-6. doi: 10.3171/2018.8.JNS181846. [Epub ahead of print] PMID: 30849758

Serrone JC, Hernesniemi J. The surgical management of previously coiled cerebral aneurysms. World Neurosurg. 2015 Apr;83(4):481-2. doi: 10.1016/j.wneu.2014.08.055. Epub 2014 sep 3.

Mascitelli JR, Moyle H, Oermann EK, Polykarpou MF, Patel AA, Doshi AH, Gologorsky Y, Bederson JB, Patel AB. An update to the Raymond-Roy Occlusion Classification of intracranial aneurysms treated with coil embolization. J Neurointerv Surg. 2015 Jul;7(7):496-502. doi: $\quad$ 10.1136/neurintsurg-2014-011258. Epub 2014 Jun 4.

Campi A, Ramzi N, Molyneux AJ, Summers PE, Kerr RS, Sneade M, Yarnold JA, Rischmiller J, Byrne JV: Retreatment of ruptured cerebral aneurysms in patients randomized by coiling or clipping in the International Subarachnoid Aneurysm Trial (ISAT). Stroke 38:1538-1544, 2007.

Civit T, Auque J: Delayed aneurysm regrowth. J Neurosurg 90:807-809, 1999.

[17]. Johnston SC, Dowd CF, Higashida RT, Lawton MT, Duckwiler GR, Gress DR; CARAT Investigators: Predictors of rehemorrhage after treatment of ruptured intracranial aneurysms: the Cerebral Aneurysm Rerupture After Treatment (CARAT) study. Stroke 39:120125, 2008.

Renowden SA, Koumellis P, Benes V, Mukonoweshuro W, Molyneux AJ, McConachie NS: Retreatment of previously embolized cerebral aneurysms: the risk of further coil embolization does not negate the advantage of the initial embolization. AJNR Am J Neuroradiol 29:1401-1404, 2008.

Raymond J, Guilbert F, Weill A, Georganos SA, Juravsky L, Lambert A, et al. Long-term angiographic recurrence after selective endovascular treatment of aneurysms with detachable coils. Stroke 2003;34:1398-403.

Raymond J, Roy D. Safety and efficacy of endovascular treatment of acutely ruptured aneurysms. Neurosurgery $1997 ; 41: 1235-44$. 
Johnston S, Dowd C, Higashida R, et al. Predictors of rehemorrhage after treatment of ruptured intracranial aneurysms: the Cerebral Aneurysm Rerupture After Treatment (CARAT) Study. Stroke 2008;39:120-5.

Ries $\mathbf{T}$, Siemonsen $\mathbf{S}$, Thomalla $\mathbf{G}$, et al. Long-term follow-up of cerebral aneurysms after endovascular therapy prediction and outcome of retreatment. AJNR Am J Neuroradiol 2007;28:1755-61.

Grunwald IQ, Balami JS, Weber $D$, et al. Different factors influence recanalisation rate after coiling in ruptured and unruptured intracranial aneurysms. CNS Neurol Disord Drug Targets 2013;12:22832.

Leng $\mathbf{B}$, Zheng $\mathbf{Y}$, Ren $\mathbf{J}$, et al. Endovascular treatment of intracranial aneurysms with detachable coils: correlation between aneurysm volume, packing, and angiographic recurrence. J Neurointerv Surg 2014;6:595-9.

Kawanabe $Y$, Sadato A, Taki W, et al. Endovascular occlusion of intracranial aneurysms with Guglielmi detachable coils: correlation between coil packing density and coil compaction. Acta Neurochir (Wien) 2001;143(5):451-5.

Sluzewski M, van Rooij WJ, Slob MJ, et al. Relation between aneurysm volume, packing, and compaction in 145 cerebral aneurysms treated with coils. Radiology2004;231:653-8.

Wakhloo AK, Gounis MJ, Sandhu JS, et al. Complex-shaped platinum coils for brain aneurysms: higher packing density, improved biomechanical stability, and midterm angiographic outcome. AJNR Am J Neuroradiol 2007;28:1395-400.

Otani $T$, Nakamura $M$, Fujinaka $T$, et al. Computational fluid dynamics of blood flow in coil-embolized aneurysms: effect of packing density on flow stagnation in an idealized geometry. Med Biol Eng Comput 2013;51:901-10.

Romani R, Lehto $H$, Laakso A, Horcajadas $A$, Kivisaari $R$, von und zu Fraunberg $M$, ef al. Microsurgery for previously coiled aneurysms: experience with 81 patients. Neurosurgery 201 1;68(1):140-53.

\section{Waldron JS, Van Halbach V, Lawton MT.} Microsurgical management of incompletely coiled and recurrent aneurysms: trends, techniques, and observations on coil extrusion. Neurosurgery 2009;64:301-17.

Sluzewski $M$, van Rooij WJ, Beute GN, Nijssen PC. Late rebleeding of ruptured intracranial aneurysms treated with detachable coils. AJNR American Journal of Neuroradiology 2005;26:2542-9. 